\title{
Urinary Tract Infections among HIV-Positive Pregnant Women in Mwanza City, Tanzania, Are High and Predicted by Low CD4+ Count
}

\author{
Tito Chaula, ${ }^{1,2}$ Jeremiah Seni, ${ }^{3,4}$ Nhandi Ng'walida, ${ }^{1,2}$ Alphaxaid Kajura, ${ }^{1,2}$ \\ Mariam M. Mirambo, ${ }^{3}$ Rebekah DeVinney, ${ }^{4}$ and Stephen E. Mshana ${ }^{3}$ \\ ${ }^{1}$ Department of Obstetrics and Gynecology, Catholic University of Health and Allied Sciences, P.O. Box 1464, \\ Bugando, Mwanza, Tanzania \\ ${ }^{2}$ Department of Obstetrics and Gynecology, Bugando Medical Centre, P.O. Box 1370, Bugando, Mwanza, Tanzania \\ ${ }^{3}$ Department of Microbiology and Immunology, Catholic University of Health and Allied Sciences, P.O. Box 1464, \\ Bugando, Mwanza, Tanzania \\ ${ }^{4}$ Department of Microbiology, Immunology and Infectious Diseases, Cumming School of Medicine, University of Calgary, \\ 3330 Hospital Dr NW, Calgary, AB, Canada T2N 4N1
}

Correspondence should be addressed to Jeremiah Seni; senijj80@gmail.com

Received 14 November 2016; Accepted 12 January 2017; Published 31 January 2017

Academic Editor: Karl Drlica

Copyright (C) 2017 Tito Chaula et al. This is an open access article distributed under the Creative Commons Attribution License, which permits unrestricted use, distribution, and reproduction in any medium, provided the original work is properly cited.

\begin{abstract}
Introduction. Urinary tract infection (UTI) among pregnant women can lead to adverse maternal and foetal outcomes. UTI has been widely studied in the general obstetric population in Tanzania; the present study evaluated the magnitude, antimicrobial resistance, and predictors of UTI among HIV-positive pregnant women. Methods. Between March and May 2016 midstream urine samples from 234 women attending prevention of mother to child transmission of HIV (PMTCT) clinics were analyzed using standard methods. Data was analyzed by STATA version 11.0. Results. The prevalence of UTI was 21.4\%, 50/234 [95\% CI: 16.126.6]. The asymptomatically significant bacteriuria was higher than symptomatically significant bacteriuria ( $16.6 \%$ versus $4.7 \%$, $p<0.001$ ). On multivariable logistic regression analysis, single marital status (OR: 2.6, 95\% CI: 1.1-6.1, and $p=0.026$ ), low CD4+ counts of $<200 / \mu \mathrm{L}$ (OR: 2.9, 95\% CI: 1.1-7.7, and $p=0.031$ ), and having UTI symptoms (OR: 2.5, 95\% CI: 1.1-6.0, and $p=0.03$ ) were independent predictors of UTI. Escherichia coli predominated (57.7\%) and exhibited a low prevalence of resistance to nitrofurantoin $(16.7 \%)$, gentamicin (10.0\%), and ceftriaxone (13.3\%). Four (13.3\%) of these were extended-spectrum beta-lactamase producers. Conclusions. A considerable proportion of HIV-positive pregnant women in Mwanza have significant bacteriuria which calls for the need to introduce routine UTI screening at PMTCT clinics to guide specific treatment and prevent associated complications.
\end{abstract}

\section{Introduction}

Urinary tract infection (UTI) is a common clinical condition among women, in particular pregnant women, due to anatomical and physiological factors [1-3]. Both symptomatic and asymptomatic UTI can negatively affect pregnant women and their foetuses [2-4]; moreover the increased likelihood of recurrence, even after successful treatment, complicates its management [5].

Human immunodeficiency virus (HIV) results in increased likelihood of opportunistic infections, including
UTI, especially in developing countries where limited health services are available $[1,6]$. Studies have shown higher prevalence of asymptomatic bacteriuria (ASB) among HIVinfected women than among uninfected pregnant women [79]. Also, the use of trimethoprim-sulfamethoxazole prophylaxis routinely in this population may potentially increase the risk of developing multidrug resistant (MDR) bacterial infections $[9,10]$.

In the northwestern part of Tanzania, a previous study conducted seven years ago revealed that 13.0 to $17.9 \%$ of pregnant women have UTI largely due to Escherichia coli 
and Enterococcus spp. [11]. Approximately 30\% of the E. coli isolates were resistant to ceftriaxone [11]. However, it is not known whether CD4+ count level, initiation of HAART, and trimethoprim-sulfamethoxazole prophylaxis, as recommended by the Ministry of Health, Community Development, Gender, Elderly and Children (MOHCDGEC) guidelines, have an impact on the prevalence of UTI, bacterial etiology, and antimicrobial resistance profiles among HIVinfected pregnant women. The present study was therefore conducted to assess the epidemiological changes pertaining the magnitude of UTI, predictor variables, and antimicrobial resistance profiles among HIV-infected pregnant women.

\section{Methods}

2.1. Study Settings, Design, and Participants. This was a hospital-based, cross-sectional study conducted from March to May 2016 at PMTCT clinics at Bugando Medical Centre (BMC), Sekou Toure Regional Hospital, Nyamagana District Hospital, and Makongoro and Buzuruga Health Centres, all located in Mwanza City, northwestern Tanzania. All HIVinfected pregnant women attending PMTCT clinics in these health facilities during the study period and who consented to participate in the study were enrolled, whereas HIV-infected pregnant women known to have urinary tract abnormalities were excluded.

2.2. Sample Size and Sampling Procedures. The minimum sample size for this study was determined with the Kish Leslie formula (1965) using the prevalence of $18.1 \%$ among HIVinfected pregnant women having asymptomatic bacteriuria in Nigeria at $95 \%$ confidence interval [9]. A total of $234 \mathrm{HIV}$ infected pregnant women were enrolled.

2.3. Data Collection and Laboratory Procedures. A structured data collection tool was used to collect sociodemographic, obstetrics, and laboratory information. Patient CD4+ counts, HAART treatment, and other clinical information were extracted from the patients' files. For participants without recent (within 6 months) determination of CD4+ counts, blood samples were taken and processed using BD FACScallibur ${ }^{\mathrm{TM}}$ to obtain current CD4+ levels [12].

Participants were instructed on how to collect cleancatch midstream urine (MSU) and place it into screwcapped, wide-mouthed, sterile disposable plastic containers [13]. Urine samples were taken to the CUHAS multipurpose laboratory and processed within an hour, or in some cases they were placed in cold box at $4^{\circ} \mathrm{C}$ and processed within 4 hours.

Urine specimens were inoculated onto MacConkey Agar and Blood Agar plates (OXOID, Hampshire, United Kingdom) and incubated at $37^{\circ} \mathrm{C}$ for 18 to 24 hours. Diagnosis of UTI was made based on the presence of $\geq 10^{5}$ colony-formingunits per milliliter of MSU of one or two types of bacterial species. Samples with more than two types of bacteria species were regarded as contamination, and sample collection was repeated [13]. Identification of bacterial isolates was done by using biochemical identification tests as previously described [13].
Antimicrobial susceptibility testing of the isolates was done using the Kirby Bauer disc diffusion test on Muller Hinton agar (OXOID, Hampshire, United Kingdom) following the Clinical Laboratory Standard Institute (CLSI) guidelines [14]. Commonly used antimicrobial agents tested for Gram-positive bacteria were penicillin (10 units), erythromycin $(15 \mu \mathrm{g})$, trimethoprim-sulfamethoxazole $(1.25 / 23.75 \mu \mathrm{g})$, tetracycline $(30 \mu \mathrm{g})$, nitrofurantoin $(300 \mu \mathrm{g})$, ciprofloxacin $(5 \mu \mathrm{g})$, and vancomycin $(30 \mu \mathrm{g})$. For Gram-negative bacteria, antimicrobial agents tested were ampicillin $(10 \mu \mathrm{g})$, amoxicillin-clavulanate $(20 / 10 \mu \mathrm{g})$, piperacillin-tazobactam (100/ $10 \mu \mathrm{g})$, trimethoprim-sulfamethoxazole $(1.25 / 23.75 \mu \mathrm{g})$, nitrofurantoin $(300 \mu \mathrm{g})$, gentamicin $(10 \mu \mathrm{g})$, ciprofloxacin $(5 \mu \mathrm{g})$, ceftriaxone $(30 \mu \mathrm{g})$, ceftazidime $(30 \mu \mathrm{g})$, and meropenem $(10 \mu \mathrm{g})$. Extended-spectrum beta-lactamase (ESBL) production was concomitantly tested in the same Muller Hinton agar plate using the double disk synergy method as previously described $[14,15]$.

2.4. Data Management. Using Excel data spread sheet, data were double entered and transferred to STATA version 11.0 for analysis. All categorical variables were summarized into proportions or frequencies, whereas continuous variables were summarized using means ( \pm standard deviations) and median (interquartile range) depending on the distribution of data. $T$-test and Wilcoxon rank-sum tests were done to compare the difference between mean and median of different groups, respectively. Univariable, followed by multivariable, logistic regression analysis for the factors with a $p$ value less than 0.2 was done to calculate odds ratio and $95 \%$ confidence interval. A $p$ value of less than 0.05 was considered significant.

2.5. Data Quality Control. Data were double entered into the excel spread sheet to ensure accuracy and reliability. Laboratory procedures were performed by laboratory scientists under the supervision of clinical microbiologists to ensure quality results. Escherichia coli ATCC 259922 and Staphylococcus aureus ATCC25923 were used as reference strains for quality control of laboratory tests.

2.6. Ethical Considerations. The study was approved by the joint CUHAS/BMC Research Ethics and Review Committee (CREC113/2016). Permission was sought from the Departments of Obstetrics and Gynecology at BMC, Sekou Toure Regional Hospital, Nyamagana District Hospital, and Makongoro and Buzuruga Health Centres. Written informed consent was obtained from every participant before data and sample collection. For women aged below 18 years, consent was sought from the parent/guardian, and they were requested to assent to the study. Results for antimicrobial susceptibility testing were timely communicated to the attending doctors/nurses for management.

\section{Results}

3.1. Sociodemographic Characteristics of the Study Participants. A total of $234 \mathrm{HIV}$-infected pregnant women, aged between 17 and 43 years, were enrolled in the study; the mean 


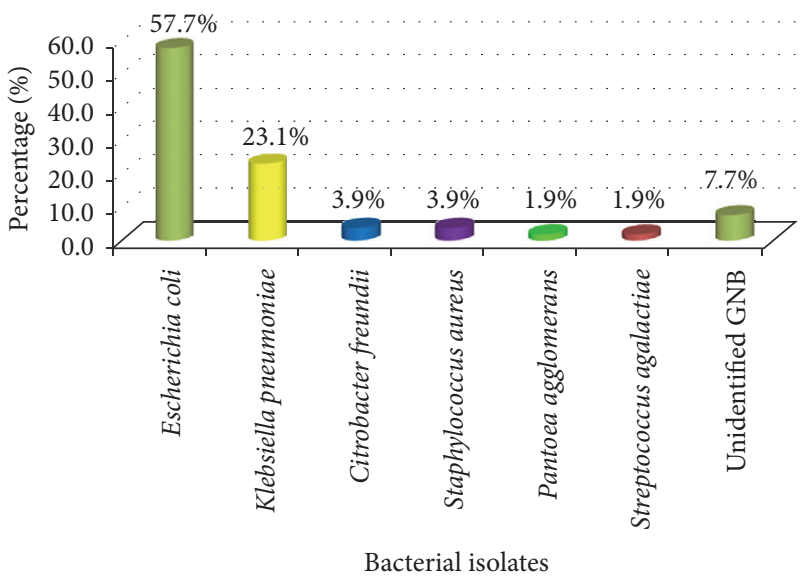

FIGURE 1: Bacterial species isolated from HIV-positive pregnant women with significant bacteriuria. Total number of bacteria is 52; two patients had dual bacterial infection; GNB: Gram-negative bacteria.

age of study population was $28 \pm 5.5$ years. All pregnant women were from urban areas. The majority of women in the study were married 203 (86.8\%) (Table 1).

\subsection{Clinical and Obstetric Characteristics of HIV-Infected} Pregnant Women. A total of 111 (47.4\%) HIV-infected pregnant women were in the 3 rd trimester. The median baseline and recent CD4+ counts were 264 (IQR 108-434) cells/ $\mu \mathrm{L}$ and 407.5 (291-594) cells $/ \mu \mathrm{L}$, respectively. The median duration on HAART was 16 (5-34) months. Of the 234 participants, 215 (91.9\%) were using trimethoprim-sulfamethoxazole prophylaxis daily (Table 2).

3.3. Prevalence of UTI and Bacterial Species Isolated. Of the 234 participants, 50 (21.4\%, 95\% CI: 16.1-26.6) had UTI. Out of 234 women, 39 (16.6\%) had asymptomatically significant bacteriuria compared to $11(4.7 \%)$ of women with symptomatically significant bacteriuria $(p<0.001)$. E. coli 30 (57.7\%) and Klebsiella pneumoniae 12 (23.1\%) were the most frequent bacterial species isolated (Figure 1).

3.4. Rate of Resistance to Antimicrobial Agents. Observed rates of resistance among E. coli were ampicillin 93.3\%, trimethoprim-sulfamethoxazole $90.0 \%$, nitrofurantoin $16.7 \%$, gentamicin $10.0 \%$, ceftriaxone $13.3 \%$, and meropenem $3.3 \%$. For K. pneumoniae isolates, the resistance rates were $100 \%$, $72.7 \%, 33.3 \%, 0.0 \%$, and $0.0 \%$ to ampicillin, trimethoprimsulfamethoxazole, nitrofurantoin, ceftriaxone, and meropenem, respectively. The proportion of extended-spectrum beta-lactamase- (ESBL-) producing Gram-negative bacteria was $8.2 \%(4 / 49)$, all of which were E. coli, $13.3 \%(4 / 30)$ (Table 3).

Two Staphylococcus aureus isolates were resistant to penicillin, trimethoprim-sulfamethoxazole, tetracycline, and nitrofurantoin; all were sensitive to erythromycin, ciprofloxacin, gentamicin, and vancomycin. Furthermore, one Streptococcus agalactiae isolate was resistant to ampicillin,
TABLE 1: Sociodemographic characteristics of HIV-infected pregnant women.

\begin{tabular}{lcc}
\hline Patient characteristics & Frequency & Percentage (\%) \\
\hline Mean age (year) & $28 \pm 5.5$ & - \\
Marital status & & \\
Married & 203 & 86.8 \\
Single & 19 & 8.1 \\
Divorced & 12 & 5.1 \\
Occupation & & \\
Peasant & 26 & 11.1 \\
Housewife & 134 & 57.3 \\
Petty trader & 64 & 27.3 \\
Employed & 10 & 4.3 \\
Religion & & \\
Christian & 177 & 75.6 \\
Muslim & 57 & 24.4 \\
Education level & & \\
None & 7 & 3.0 \\
Primary & 176 & 75.2 \\
Secondary & 48 & 20.5 \\
College & 3 & 1.3 \\
\hline Continous variale & &
\end{tabular}

${ }^{*}$ Continuous variable.

trimethoprim-sulfamethoxazole, nitrofurantoin, and erythromycin; it was sensitive to ciprofloxacin, gentamicin, and vancomycin.

3.5. Factors Associated with UTI among HIV-Infected Pregnant Women. Multivariable logistic regression analysis showed that being single (OR: 2.6, $95 \mathrm{CI}: 1.1-6.1$, and $p=0.026$ ), current low CD4+ counts of $<200 / \mu \mathrm{L}$ (OR: 2.9 , 95\% CI: 1.17.7 , and $p=0.031$ ), and UTI symptoms (OR: 2.5 , 95\% CI: $0.6-8.3$, and $p=0.03$ ) were independent predictors of UTI among HIV-positive pregnant women. Coitus frequency was also associated with UTI on bivariate analysis $(12.12 \%$ and $25.0 \%$ among those practicing coitus more than two and one times per week, resp.). Nevertheless, this variable was omitted in multivariate analysis due to its collinearity with marital status (Table 4).

\section{Discussion}

UTI is common among HIV-infected pregnant women, and, if left untreated, it can lead to poor maternal and foetal outcomes $[4,6]$. The prevalence of UTI in this study was higher than approximately 15\% observed in the general obstetric population in the same region measured seven years ago [11]. In the previous study, significantly higher rates in symptomatically significant bacteriuria was observed [11], while in the present study more women presented with asymptomatic bacteriuria. This connotes a rising trend of UTI, from approximately $15 \%$ in 2009 to $21 \%$ in the current study, with preponderance of UTI in the vulnerable HIVinfected pregnant women.

In this study, E. coli was the most common uropathogen isolated, a result that is comparable to the previous findings 
TABLE 2: Clinical and obstetric characteristics of HIV-infected pregnant women.

\begin{tabular}{|c|c|c|}
\hline Patient characteristics & Frequency & Percentage (\%) \\
\hline \multicolumn{3}{|l|}{ Gravidity } \\
\hline Gravida 1 & 35 & 14.9 \\
\hline Gravida 2 & 57 & 24.4 \\
\hline$\geq$ Gravida 3 & 142 & 60.7 \\
\hline \multicolumn{3}{|l|}{ Parity } \\
\hline Nulliparity & 43 & 18.4 \\
\hline Para 1-3 & 149 & 63.7 \\
\hline$\geq$ Para 4 & 42 & 17.9 \\
\hline \multicolumn{3}{|l|}{ Gestation age } \\
\hline 1st trimester & 13 & 5.6 \\
\hline 2nd trimester & 110 & 47.0 \\
\hline 3rd trimester & 111 & 47.4 \\
\hline \multicolumn{3}{|l|}{ Coitus per week } \\
\hline$\leq 1$ & 168 & 71.8 \\
\hline$\geq 2$ & 66 & 28.2 \\
\hline Median baseline CD4* & 264 (IQR 108-434) & \\
\hline \multicolumn{3}{|l|}{ Baseline CD4 } \\
\hline$\leq 200$ & 141 & 60.3 \\
\hline$>200$ & 93 & 39.7 \\
\hline Median current $C D 4^{*}$ & 407.5 (IQR 291-583) & \\
\hline \multicolumn{3}{|l|}{ Current CD4 } \\
\hline$<200$ & 21 & 9.0 \\
\hline$\geq 200$ & 213 & 91.0 \\
\hline Median HAART duration (months)* & 16 (IQR 5-34) & \\
\hline \multicolumn{3}{|l|}{ Duration on HAART (months) } \\
\hline$\leq 12$ & 105 & 44.9 \\
\hline $13-24$ & 41 & 17.5 \\
\hline$\geq 25$ & 88 & 37.6 \\
\hline \multicolumn{3}{|l|}{ Trimethoprim-sulfamethoxazole use } \\
\hline Yes & 215 & 91.9 \\
\hline No & 19 & 8.1 \\
\hline \multicolumn{3}{|l|}{ Urinary symptoms } \\
\hline Yes & 27 & 11.5 \\
\hline No & 207 & 88.5 \\
\hline
\end{tabular}

${ }^{*}$ Median with interquartile range; IQR: interquartile range; HAART: highly active antiretroviral therapy.

TABle 3: Antimicrobial resistance profiles among Gram-negative bacteria isolates.

\begin{tabular}{|c|c|c|c|c|c|c|c|c|c|}
\hline Bacteria & $\begin{array}{l}\text { AMP } \\
n(\%)\end{array}$ & $\begin{array}{c}\text { SXT } \\
n(\%)\end{array}$ & $\begin{array}{c}\text { NF } \\
n(\%)\end{array}$ & $\begin{array}{c}\text { CIP } \\
n(\%)\end{array}$ & $\begin{array}{c}\mathrm{GN} \\
n(\%)\end{array}$ & $\begin{array}{l}\text { AMC } \\
n(\%)\end{array}$ & $\begin{array}{l}\text { CRO } \\
n(\%)\end{array}$ & $\begin{array}{l}\text { MEM } \\
n(\%)\end{array}$ & $\operatorname{ESBL} n(\%)$ \\
\hline $\begin{array}{l}\text { E. coli } \\
(N=30)\end{array}$ & 28 (93.3) & $27(90.0)$ & $5(16.7)$ & $4(13.3)$ & $3(10)$ & $13(43.3)$ & $4(13.3)$ & $1(3.3)$ & $4(13.3)$ \\
\hline $\begin{array}{l}\text { K. pneumoniae } \\
(N=12)\end{array}$ & $11(100)$ & $8(72.7)$ & $4(33.3)$ & $1(9.1)$ & $0(0)$ & $6(54.5)$ & $0(0.0)$ & $0(0)$ & $0(0.0)$ \\
\hline $\begin{array}{l}\text { Other GNB } \\
(N=6)\end{array}$ & $6(100)$ & $5(83.3)$ & $0(0)$ & $0(0)$ & $2(33.3)$ & $2(33.3)$ & $1(16.7)$ & $0(0)$ & $0(0)$ \\
\hline
\end{tabular}

AMP: ampicillin; SXT: trimethoprim-sulfamethoxazole; NF: nitrofurantoin; AMC: amoxicillin-clavulanate; CRO: ceftriaxone; MEM: meropenem; GNB: Gram-negative bacteria; other GNB: Citrobacter freundii (2), Pantoea agglomerans (1), and unidentified GNB (3). 
TABLE 4: Univariable and multivariable logistic regression analysis of the factors associated with UTI among HIV-infected pregnant women.

\begin{tabular}{|c|c|c|c|c|c|}
\hline Characteristics & $\begin{array}{c}\text { UTI positivity } \\
n(\%)\end{array}$ & $\begin{array}{c}\text { Univariable } \\
\text { OR (95\% CI ) }\end{array}$ & $p$ value & $\begin{array}{l}\text { Multivariable } \\
\text { OR }(95 \% \text { CI })\end{array}$ & $p$ value \\
\hline Age ${ }^{*}$ & $50(28.6 \pm 5.6)$ & $0.97(0.91-1.02)$ & 0.253 & & \\
\hline \multicolumn{6}{|l|}{ Marital status } \\
\hline Married (203) & $38(18.7)$ & 1 & & & \\
\hline Single (31) & $12(38.7)$ & $2.74(1.22-6.13)$ & 0.012 & $2.61(1.12-6.09)$ & 0.026 \\
\hline \multicolumn{6}{|l|}{ Occupation } \\
\hline Peasant (26) & $3(11.5)$ & 1 & & & \\
\hline Employed (74) & $35(26.1)$ & $1.48(0.38-5.73)$ & 0.567 & $1.4(0.35-5.7)$ & 0.623 \\
\hline Housewife (134) & $12(16.2)$ & $2.71(0.77-9.59)$ & 0.122 & $2.24(0.61-8.2)$ & 0.223 \\
\hline \multicolumn{6}{|l|}{ Religion } \\
\hline Muslim (57) & $12(21.1)$ & 1 & & & \\
\hline Christian (177) & $38(21.5)$ & $1.15(0.49-2.13)$ & 0.947 & & \\
\hline \multicolumn{6}{|l|}{ Education level } \\
\hline Secondary (57) & $10(19.6)$ & 1 & & & \\
\hline Primary (177) & $40(21.9)$ & $1.16(0.53-2.49)$ & 0.729 & & \\
\hline Gravidity $^{* *}$ & 3 (IQR 2-4) & $0.88(0.73-1.07)$ & 0.21 & & \\
\hline Gestation age $^{* *}$ & 28 (IQR 20-32) & $1.03(0.98-1.07)$ & 0.24 & & \\
\hline \multicolumn{6}{|l|}{ Coitus per week } \\
\hline$\geq 2(66)$ & $8(12.1)$ & 1 & & & \\
\hline$\leq 1(168)$ & $42(25.0)$ & $2.42(1.07-5.47)$ & 0.034 & & \\
\hline \multicolumn{6}{|l|}{ Baseline CD4 } \\
\hline$>200(93)$ & $25(17.7)$ & 1 & & & \\
\hline$\leq 200(141)$ & $25(26.9)$ & $1.7(0.908-3.20)$ & 0.97 & & \\
\hline \multicolumn{6}{|l|}{ Current CD4 } \\
\hline$\geq 200(213)$ & $41(19.3)$ & 1 & & & \\
\hline$<200(21)$ & $9(42.9)$ & $3.15(1.24-7.97)$ & 0.02 & $2.92(1.10-7.71)$ & 0.031 \\
\hline Duration ART (months) $234^{* *}$ & 15.5 (IQR 6-30) & $1.0(0.99-1.02)$ & 0.93 & & \\
\hline \multicolumn{6}{|l|}{ SXT use } \\
\hline No & $45(20.9)$ & 1 & & & \\
\hline Yes & $5(26.3)$ & $1.35(0.46-3.94)$ & 0.58 & & \\
\hline \multicolumn{6}{|l|}{ UTI symptoms } \\
\hline No 207 & $39(18.8)$ & 1 & & & \\
\hline Yes 27 & $11(40.7)$ & $2.99(1.27-6.88)$ & 0.01 & $2.52(1.05-6.04)$ & 0.03 \\
\hline
\end{tabular}

${ }^{*}$ Mean and standard deviation (SD), ${ }^{* *}$ median with interquartile range (IQR), and SXT: trimethoprim-sulfamethoxazole.

at BMC, Muhimbili, and Hydom in Tanzania among the general obstetric population $[4,11,16]$. The similarity of these results may be due to the predominance of $E$. coli in different populations in these settings [17-20] and the anatomical proximity between anus, vagina, and urethra in relation to the hygienic behavior.

The low level of resistance among uropathogens to nitrofurantoin, gentamicin, and ceftriaxone reiterates the fact that these antimicrobial agents may be judiciously used as potential therapeutic options in this population. Of note, when comparing the current findings with the previous study in the same setting [11], there has been a rise in resistance trends for trimethoprim-sulfamethoxazole (64.7\% to $90.0 \%)$, nitrofurantoin $(5.9 \%$ to $16.7 \%)$, and gentamicin $(5.9 \%$ to
$10.0 \%)$ among E. coli isolates. High levels of resistance to commonly used antimicrobial agents, such as ampicillin and trimethoprim-sulfamethoxazole, were also reported in Ghana and Ethiopia [21, 22]. These results emphasize the need to strengthen AMR control strategies in developing countries so that antimicrobial agents can be preserved for future generations. ESBL production was found in $13.3 \%$; this is worrisome as women with these pathogens were outpatients and therefore represent community acquired UTI. One plausible explanation may be related to previous exposure to antimicrobial agents, which then selects drug-resistant mutants in the digestive tract. The mutant strains in turn contaminate the urinary system and cause reinfection. This emphasizes the need to strengthen antimicrobial stewardship 
and strategies that will change human behavior on issues related to antibiotic use, disposal, and improved hygienic measures.

Several studies have documented various predictors of UTI $[8,9]$. In the present study, single marital status, current lower CD4+ count below 200 cells $/ \mu \mathrm{L}$, and the presence of symptoms predicted UTI. Several other studies have shown no association of UTI and marital status $[9,11]$. Although no clear explanation was revealed by the present study, this may be attributable to the differences in cultural practice, hygiene, and norms on sex issues in different areas [23].

Similar to other reports $[7,9,24]$, low CD4+ counts in this study predicted UTI among HIV-infected pregnant women, an observation that could be explained by the severity of immunosuppression and the increased likelihood for opportunistic infections, including UTI. In light of this finding, integration of routine $\mathrm{CD} 4+$ count measurement and UTI screening should be a continuing program to ensure rational and prompt management of this population.

Also, the presence of UTI symptoms among HIV-infected pregnant women was an independent predictor of UTI. This is similar to study findings reported elsewhere [25]. Because both symptomatic and asymptomatic bacteriuria can have negative maternal and foetal outcomes, routine UTI screening is highly recommended.

The use of trimethoprim-sulfamethoxazole as prophylaxis was not associated with UTI in this study, similar to another study in our setting among nonpregnant, HIVinfected individuals [20]. In contrast, a study performed in Uganda found that trimethoprim-sulfamethoxazole use was protective against significant bacteriuria [24]. The difference could be explained by other factors, such as CD4 counts. However, the high resistance prevalence emphasizes the fact that trimethoprim-sulfamethoxazole may not work as a therapeutic option for HIV patients with UTI.

\section{Conclusion}

The prevalence of UTI among HIV-infected pregnant women is high and is predicted by low CD $4+$ count of $<200$ cells $/ \mu \mathrm{L}$, being single, and exhibiting UTI symptoms. We observed a predominance of $E$. coli exhibiting high resistance to ampicillin and trimethoprim-sulfamethoxazole compared to lower values for nitrofurantoin, gentamicin, and ceftriaxone.

We recommend introduction of routine UTI screening at PMTCT clinics among pregnant women at booking to guide specific treatment and prevent associated complications. Low CD4+ count $<200$ cells $/ \mu \mathrm{L}$, being single, and the presence of urinary tract infection symptoms can be used as predictors of UTI when planning for selective screening in areas where urine culturing is not routinely performed. Studies evaluating obstetric and neonatal outcomes among HIV-infected pregnant women with UTI, as well as molecular characterization of these strains in the context of infection prevention and control, would be of interest for the future studies.

\section{Additional Points}

Study Limitations. HIV viral load, which has been reported to be potential predictor for UTI, was not measured in this study due to financial constraints.

\section{Competing Interests}

The authors declare that they have no conflict of interests.

\section{Authors' Contributions}

Tito Chaula, Jeremiah Seni, Nhandi Ng'walida, Alphaxaid Kajura, Rebekah DeVinney, and Stephen E. Mshana conceived and executed the study. Tito Chaula, Nhandi Ng'walida, and Alphaxaid Kajura were involved in managing patients. Tito Chaula, Jeremiah Seni, and Mariam M. Mirambo collected the data and samples. Jeremiah Seni, Mariam M. Mirambo, and Stephen E. Mshana performed laboratory procedures. Tito Chaula, Jeremiah Seni, and Stephen E. Mshana analyzed data. Jeremiah Seni wrote the first draft of the manuscript, which was critically reviewed by all authors. All authors have approved the final version of the manuscript. Tito Chaula and Jeremiah Seni are equal contributors.

\section{Acknowledgments}

The authors are thankful to pregnant women involved in this study as well as staff in the Department of Obstetrics \& Gynecology in various health facilities for their support. Dr. Benson R. Kidenya, Martha F. Mushi, Mr. Vitus Silago, and Mr. Makoye Shaban are thanked for their technical inputs. This work was supported by Nkinga Referral Hospital and Nkinga Friends to Tito Chaula and by CUHAS to Jeremiah Seni and Stephen E. Mshana.

\section{References}

[1] B. Foxman, "Epidemiology of urinary tract infections: incidence, morbidity, and economic costs," The American Journal of Medicine, vol. 113, supplement 1, pp. 5S-13S, 2002.

[2] J. F. M. Santos, R. M. Ribeiro, P. Rossi et al., "Urinary tract infections in pregnant women," International Urogynecology Journal and Pelvic Floor Dysfunction, vol. 13, no. 3, pp. 204-209, 2002.

[3] A. B. MacLean, "Urinary tract infection in pregnancy," International Journal of Antimicrobial Agents, vol. 17, no. 4, pp. 273-277, 2001.

[4] B. Blomberg, B. E. Olsen, S. G. Hinderaker et al., "Antimicrobial resistance in urinary bacterial isolates from pregnant women in rural Tanzania: implications for public health," Scandinavian Journal of Infectious Diseases, vol. 37, no. 4, pp. 262-268, 2005.

[5] J. E. Delzell Jr. and M. L. Lefevre, "Urinary tract infections during pregnancy," American Family Physician, vol. 61, no. 3, pp. 713-721, 2000.

[6] UNAIDS: 2014 Progress Report on the Global Plan, Joint United Nations Programme on HIV/AIDS (UNAIDS), 2014.

[7] O. A. Awolude, O. A. Adesina, A. Oladokun, W. B. Mutiu, and I. F. Adewole, "Asymptomatic bacteriuria among HIV positive pregnant women," Virulence, vol. 1, no. 3, pp. 130-133, 2010. 
[8] T. A. Widmer, G. Theron, and D. Grove, "Prevalence and risks of asymptomatic bacteriuria among HIV-positive pregnant women," Southern African Journal of Epidemiology and Infection, vol. 25, no. 1, pp. 28-32, 2010.

[9] O. C. Ezechi, C. V. Gab-Okafor, D. A. Oladele et al., "Prevalence and risk factors of asymptomatic bacteriuria among pregnant Nigerians infected with HIV," Journal of Maternal-Fetal and Neonatal Medicine, vol. 26, no. 4, pp. 402-406, 2013.

[10] J. Walter, M. Mwiya, N. Scott et al., "Reduction in preterm delivery and neonatal mortality after the introduction of antenatal cotrimoxazole prophylaxis among HIV-infected women with low CD4 cell counts," Journal of Infectious Diseases, vol. 194, no. 11, pp. 1510-1518, 2006.

[11] A. Masinde, B. Gumodoka, A. Kilonzo, and S. E. Mshana, "Prevalence of urinary tract infection among pregnant women at Bugando Medical Centre, Mwanza, Tanzania," Tanzania Journal of Health Research, vol. 11, no. 3, pp. 154-159, 2009.

[12] J. Manasa, H. Musabaike, C. Masimirembwa, E. Burke, R. Luthy, and J. Mudzori, "Evaluation of the partec flow cytometer against the BD FACSCalibur system for monitoring immune responses of human immunodeficiency virus-infected patients in Zimbabwe," Clinical and Vaccine Immunology, vol. 14, no. 3, pp. 293-298, 2007.

[13] E. W. Koneman, S. D. Allen, W. M. Janda, P. C. Schreckenberger, and W. C. Winn Jr., Color Atlas and Textbook of Diagnostic Microbiology, Lippincott, 1997.

[14] CLSI, "Perfomance standards for antimicrobial susceptibility testing; twenty first information supplement," CLSI Document M100-S21, Clinical and Laboratory Standards Institute, Wayne, $\mathrm{Pa}$, USA, 2011.

[15] S. E. Mshana, E. Kamugisha, M. Mirambo, T. Chakraborty, and E. F. Lyamuya, "Prevalence of multiresistant gram-negative organisms in a tertiary hospital in Mwanza, Tanzania," BMC Research Notes, vol. 2, article no. 49, 2009.

[16] S. J. Moyo, S. Aboud, M. Kasubi, and S. Y. Maselle, "Bacterial isolates and drug susceptibility patterns of urinary tract infection among pregnant women at Muhimbili National Hospital in Tanzania," Tanzania Journal of Health Research, vol. 12, no. 4, pp. 236-240, 2010.

[17] E. Festo, B. R. Kidenya, A. Hokororo, and S. E. Mshana, "Predictors of urinary tract infection among febrile children attending at Bugando Medical Centre Northwestern, Tanzania," Archives of Clinical Microbiology, vol. 2, no. 5, 2011.

[18] M. Ahmed, N. Moremi, M. M. Mirambo et al., "Multi-resistant gram negative enteric bacteria causing urinary tract infection among malnourished underfives admitted at a tertiary hospital, northwestern, Tanzania," Italian Journal of Pediatrics, vol. 41, article 44, 2015.

[19] N. Moremi, M. F. Mushi, M. Fidelis, P. Chalya, M. Mirambo, and S. E. Mshana, "Predominance of multi-resistant gramnegative bacteria colonizing chronic lower limb ulcers (CLLUs) at Bugando Medical Center," BMC Research Notes, vol. 7, no. 1, article 211, 2014.

[20] K. J. Marwa, M. F. Mushi, E. Konje, P. E. Alele, J. Kidola, and M. M. Mirambo, "Resistance to cotrimoxazole and other antimicrobials among isolates from HIV/AIDS and Non-HIV/AIDS patients at bugando medical centre, Mwanza, Tanzania," AIDS Research and Treatment, vol. 2015, Article ID 103874, 8 pages, 2015.

[21] T. Demilie, G. Beyene, S. Melaku, and W. Tsegaye, "Urinary bacterial profile and antibiotic susceptibility pattern among pregnant women in north west Ethiopia," Ethiopian Journal of Health Sciences, vol. 22, no. 2, pp. 121-128, 2012.

[22] G. Ferede, G. Yismaw, Y. Wondimeneh, and Z. Sisay, "The prevalence and antimicrobial susceptibility pattern of bacterial uropathogens isolated from pregnant women," European Journal of Experimental Biology, vol. 2, no. 5, pp. 1497-1502, 2012.

[23] F. N. Amiri, M. H. Rooshan, M. H. Ahmady, and M. J. Soliamani, "Hygiene practices and sexual activity associated with urinary tract infection in pregnant women," Eastern Mediterranean Health Journal, vol. 15, no. 1, pp. 104-110, 2009.

[24] M. Luyiga, Prevalence, sensitivity patterns and factors associated with asymptomatic bacteriuria among HIV positive pregnant women in Mulago Hospital [M.S. dissertation], 2012.

[25] L. G. Giesen, G. Cousins, B. D. Dimitrov, F. A. van de Laar, and T. Fahey, "Predicting acute uncomplicated urinary tract infection in women: a systematic review of the diagnostic accuracy of symptoms and signs," BMC Family Practice, vol. 11, no. 1, article 78, 2010. 

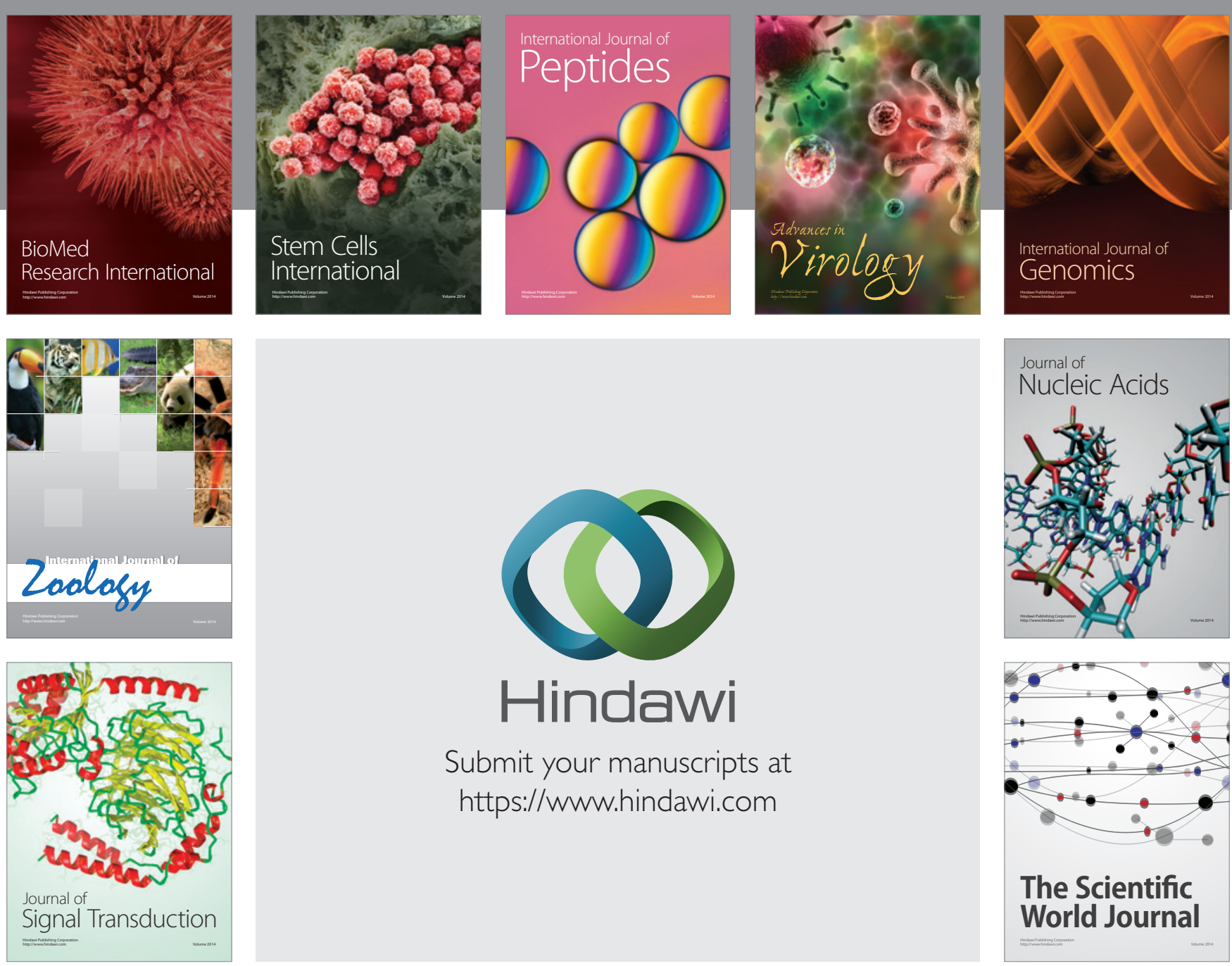

Submit your manuscripts at

https://www.hindawi.com
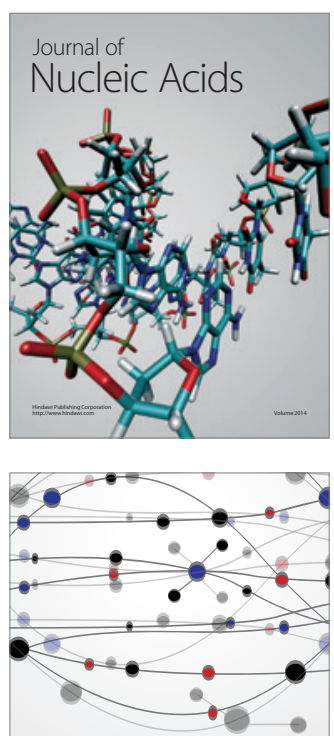

The Scientific World Journal
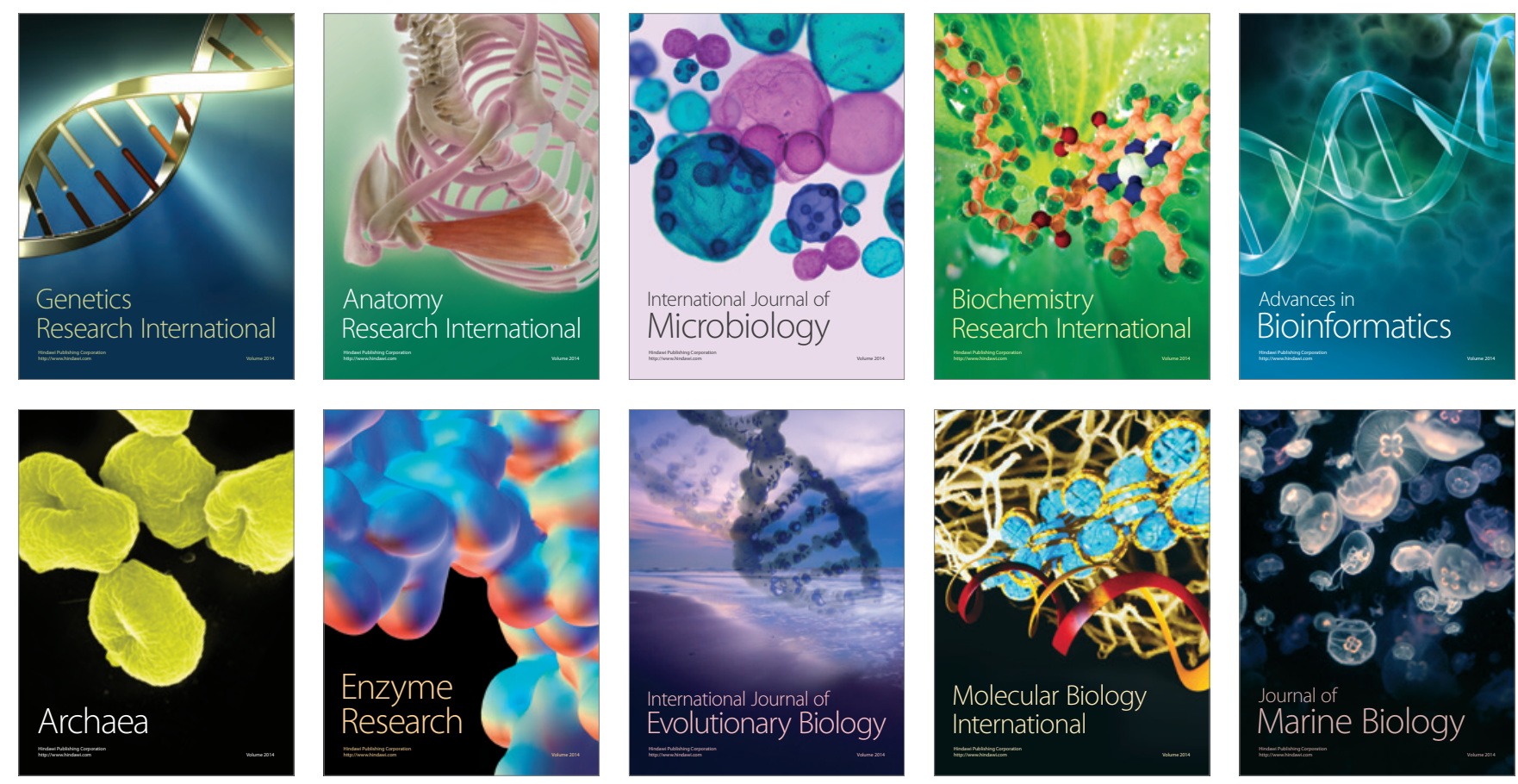